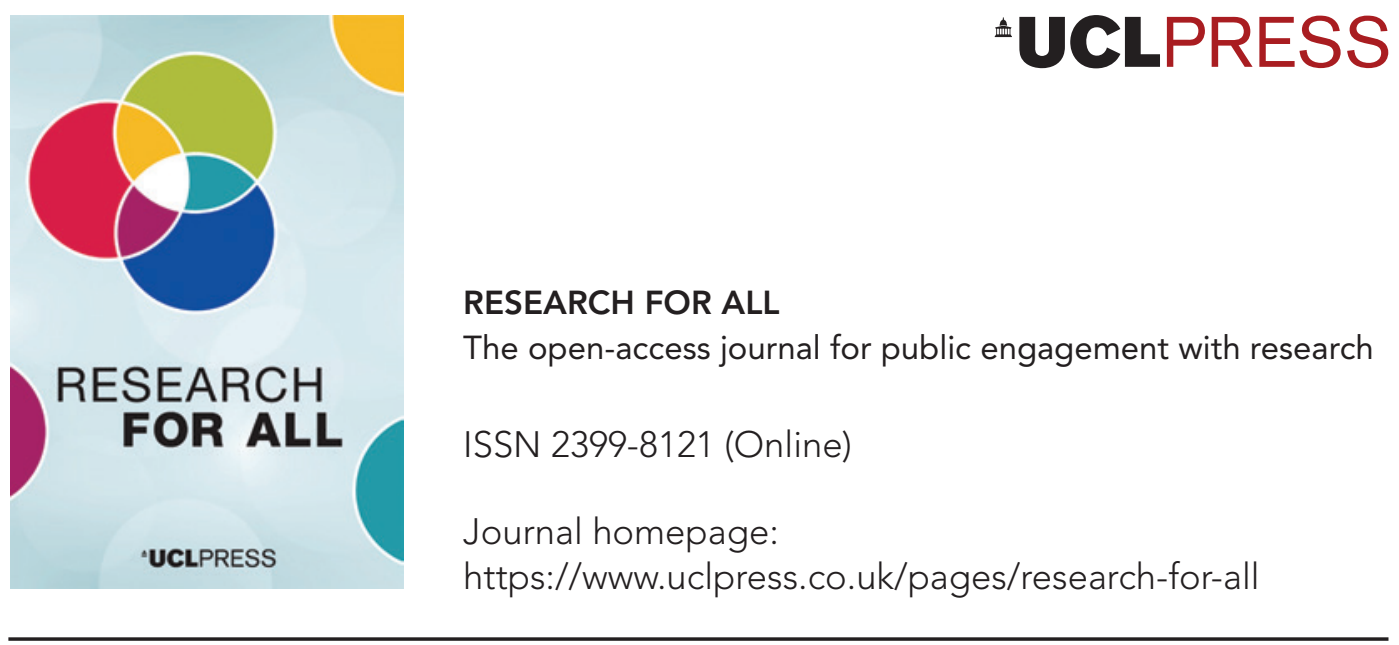

\title{
Co-producing artistic approaches to social cohesion
}

Katy Goldstraw (D), Andrew McMillan, Helen Mort, Kate Pahl(D, Steve Pool, Zahir Rafiq and Zanib Rasool(D)

\section{How to cite this article}

Goldstraw, K., McMillan, A., Mort, H., Pahl, K., Pool, S., Rafiq, Z. and Rasool, Z. (2020) 'Co-producing artistic approaches to social cohesion'. Research for All, 4 (2), 257-75. Online. https://doi.org/10.14324/RFA.04.2.09

Submission date: 24 April 2019

Accepted date: 21 November 2019

Publication date: 22 September 2020

\section{Peer review}

This article has been peer-reviewed through the journal's standard double-blind peer review, where both the reviewers and authors are anonymized during review.

\section{Copyright}

(C) 2020 Goldstraw, McMillan, Mort, Pahl, Pool, Rafiq and Rasool. This is an open-access article distributed under the terms of the Creative Commons Attribution Licence (CC BY) 4.0 https://creativecommons.org/licenses/by/4.0/, which permits unrestricted use, distribution and reproduction in any medium, provided the original author and source are credited.

\section{Open access}

Research for All is a peer-reviewed open-access journal. 


\title{
Co-producing artistic approaches to social cohesion
}

\author{
Katy Goldstraw* - Staffordshire University, UK \\ Andrew McMillan - Manchester Metropolitan University, UK \\ Helen Mort - Manchester Metropolitan University, UK \\ Kate Pahl - Manchester Metropolitan University, UK \\ Steve Pool - Visual artist \\ Zahir Rafiq - Visual artist \\ Zanib Rasool - University of Sheffield, UK
}

\begin{abstract}
This paper examines the potential of co-produced arts-based methodologies through the lens of a social cohesion project, from the perspectives of five artists. Arts methodologies can be useful in working across different disciplines and across university and community boundaries to create equitable knowledge production processes. The ways in which art is used in community settings as a mode of collaboration are explored, using the reflections from five artists who were involved in the social cohesion project together. This paper argues that coproducing artistic approaches to social cohesion is a complex, multilayered and sometimes fragile process, but that recognizing and discussing understandings of the role of power and voice within co-produced projects enables effective team communication.
\end{abstract}

Keywords: co-production, participation, arts-based-research, social cohesion, power, voice

\section{Key messages}

- It is important to engage artists in co-produced research from the beginning, to recognize the variations of power held in a project and to take steps to empower artistic voice.

- Valuing the artists is central; artists can offer an alternative perspective on community relationships and social cohesion. The arts offer the power of the imagination, the creative freedom to see beyond a current reality, in order to build a vision of social cohesion.

- Co-producing artistic approaches to social cohesion is a complex, multilayered and sometimes fragile process, but recognizing, discussing and sharing understandings of the role, power and voice within the co-produced voice enables effective team communication.

\section{Introduction}

In this paper, the relationship between different arts methodologies as a method of building social cohesion is examined, through the lens of a co-produced arts project. The paper discusses this from the perspectives of the artists on the project. 
Social cohesion is a contested term. Various definitions of social cohesion exist, drawing on notions of trust, identity, belonging and dialogue (Jones, 2015). Social cohesion, therefore, is 'a descriptive multi-faceted and gradual phenomenon attributed to a collective, indicating a quality of togetherness' (Schiefer and Van der Noll, 2017: 2). For the purpose of this paper, social cohesion can be broadly defined as:

... a state of affairs concerning both the vertical and horizontal interactions of society as characterised by a set of attitudes and norms that includes trust, a sense of belonging and the willingness to participate and help, as well as their behavioural manifestations. (Chan et al., 2006: 290)

The potential of co-produced arts methodologies to build social cohesion is undertheorized. In recognizing multiple knowledge forms, using artistic-based approaches to social cohesion seeks to create a space that values non-academic knowledges (Vasudevan, 2011). By using arts-based practice to reduce the focus on the written word and foregrounding other means of communication (Foster, 2012), the arts allow a diversity of representation (Goodman, 1968). Using arts-based approaches to social cohesion allows participants to enter discussions at the point at which they feel most comfortable expressing their knowledge (Kumasi, 2011). In valuing multiple knowledges - experiential, artistic and academic - artistic methodologies offer the opportunities to produce different kinds of knowledge (Facer and Pahl, 2017). This knowledge can be important for expressing notions of belonging and identity, which can be explored using arts-based methodologies to build social cohesion.

This paper begins with a critical reflection on the potential of arts methodologies to contribute to social cohesion. Then, through a series of interviews and a participatory reflection workshop with artists involved in a co-produced social cohesion project, the paper specifically reflects on how artistic methods can contribute to the building of social cohesion, looked at from an artist's perspective. Illustrative examples from artists are used in order to explore the issues in the project, including the relationship between co-production and artistic methodologies. Various themes emerged from the research, including the importance of foregrounding artistic understandings and prioritizing artistic relationships with communities. Many of the artists involved in the project had ties of trust and strong existing relationships with communities, and could contribute their whole selves (not simply their artistic selves) to the project. Developing shared understandings was important throughout the project, which included defining participants' roles as artists and establishing a strong artistic voice within the three settings used by the project. A further key theme was that of valuing specific arts specialisms, including community art, poetry and music. The issue of art as a process or product was a tension for the project. Whether the process of using arts-based methodologies held value for social cohesion, or whether communities in fact valued as important an artistic product at the end of the process, was a contested issue for the artists involved in the project. This paper recognizes the history of socially engaged and community art (Pool, 2018), and seeks to reflect on this tension from the perspective of the artists involved in the project. The paper explores the aspirations of an arts-based approach, arguing that co-producing artistic methodologies to build social cohesion is a complex, multilayered and sometimes fragile process. However, in recognizing and discussing understandings of the role of power and voice within co-produced projects, effective team communication can be enabled. 


\section{Creating potential for arts methodologies to create space for social cohesion}

This paper explores the aspirations of a co-produced arts-based approach to build social cohesion. Co-production draws on a variety of approaches to collaborative work, such as action research and participatory research, which highlight the importance of collaborative knowledge creation (Coghlan and Brydon-Miller, 2014). Research methodology greatly influences both the research process and its research outcomes (Datta et al., 2015). Arts-based approaches can refocus power and control into the hands of the community (Finley, 2008: 72). Co-produced arts methodologies respect and engage the experiences of people, offering research participants more control over the research process and influence over how findings are used.

Co-production is the co-creation of knowledge with participants of a research project (Facer and Pahl, 2017). Co-production as an approach values multiple viewpoints and creates space for differences of opinion to be recognized and included within the research. In co-produced research, participants are encouraged to construct their own knowledge, and consider the power dynamics with which knowledge is used by the dominant cultures (Reason, 1998). In enabling the authorship of an artistic process to sit collaboratively with a team of authors, co-production holds the potential to develop a conversation that recognizes multiple viewpoints and points of difference (Hirsch and Miessen, 2012). In this project, co-production and artistic practice were combined. Arts-based approaches here included visual and written art forms, including portraiture, poetry and collage. There are challenges to the artistic process of co-production, and recognizing the contested nature of terms such as 'social cohesion', 'community' and 'socially engaged art' is important to understanding the multiple knowledge brought to the artists' discussions. The project was developed in areas of Sheffield and Rotherham experiencing racial tensions (Campbell et al., 2018). Using arts-based approaches to develop social cohesion was seen to hold an emancipatory research purpose (Facer and Pahl, 2017).

\section{Social cohesion: A contested term}

The project sought to develop the potential for arts-based practice to create a space for social cohesion. It should, however, be recognized that 'social cohesion' is a contested term, which can be discussed from three linked yet competing perspectives. The meaning of social cohesion is fluid and shifting, often context specific and linked to broader notions of identity, belonging, power and inequality (Jones, 2015). Social cohesion can be viewed from the perspective of inclusion or exclusion from society, as a study of institutions and governance, or as a study of networks and belonging (Schiefer and Van der Noll, 2017). Despite its frequent politicization, there are two broad approaches to understanding social cohesion: the first emphasizes the shared values that bind a community, and the second emphasizes the quality of these social relationships (Delhey, 2007). Social cohesion is perhaps one of 'those hybrid mental constructions' (Schiefer and Van der Noll, 2017: 579) that is adaptable to a variety of situations but lacks a clear definition.

Cohesion can be multilayered with identity, belonging and power holding different meanings for members of the same community of varying genders, sexualities and community status. Using artistic approaches to building social cohesion allows a consideration of layered identities; to view questions of identity in visual, poetic and narrativized ways that offer an alternative perspective on identity (Facer and Pahl, 2017). Notions of belonging, trust and reciprocity can be addressed through visions of melting pots, bricolage, salads and mosaics, allowing a visual exploration of situated meanings of social cohesion (Pahl and Goldstraw, 2018). 


\section{Community: A contested term}

Throughout the paper, the terms 'community' and 'community practitioner' are referred to. The paper seeks to frame the concept of community and community development around Etzioni's (1993) notion of communitarianism. Communitarianism argues that with rights come responsibilities; citizens need to engage with these responsibilities in order to create a better society. Etzioni's (ibid.) communitarianism aims to reinvigorate citizenship to help to reshape the social, philosophical and political agenda. It is these connections between people that build social cohesion. Here, arts-based approaches can make a contribution to building safe spaces that value multiple knowledge forms, developing connections and building societal ties. In the context of this paper, community practitioners are engaged in community development, framed around the notion of communitarianism, with communities. The concept of community and communitarianism (Putnam, 2000; Etzioni, 1993) has aimed to 'formalise a cogent and coherent defence and celebration of community life' (Sage, 2012: 2). The project upon which this paper is based developed a collaborative methodology that saw community practitioners working alongside artists and academics, using arts-based approaches to building social cohesion. This paper discusses the use of artistic practices for social cohesion with communities and community practitioners.

It is important to recognize that 'community' is also a contested term. People have multiple identities and networks that reach beyond their neighbourhood (Sparke, 2008). The term 'community' can be discussed in terms of communities of geography and communities of identity (Sparke, 2008). 'Community' as a term can be critiqued here for its failure to recognize the intersection of multiple inequalities (Walby, 1990; Hancock et al., 2012). Gender and intersectionality (Crenshaw, 1991) are fundamental to considering inequalities within communities. However, it is arguably naive to consider communities as 'communities of mythic unity' (Kwon, 2002: 118). The term 'community' viewed in terms of community cohesion is arguably the 'ontological equivalent of kitsch' (Kocur and Leung, 2005: 11). Communities are diverse within themselves and conflicted, and arts-based approaches can enhance reflexivity and encourage selfcriticism within and beyond communities of geography, interest and identity.

\section{Socially engaged art: A contested term}

In using arts-based practice to build social cohesion, art can become a social form (Bishop, 2004), and can therefore hold political and emancipatory functions. Artistic methodologies, however, have complex histories (Kester, 2004). The history of art as a social process (Pool, 2018) can be tracked to the art of the Enlightenment, to the avantgarde, to relational and dialogical aesthetics. In Conversation Pieces, Kester (2004) provides a detailed exploration of this movement of art from a document to a dialogue with the present. This approach has deep and complex roots in the history of art and cultural activism (Kocur and Leung, 2005), and it is part of a new genre of public art that reflects the hybrid liminal nature of this artistic approach. In revisiting and reflecting, arts methodologies can 'call for and resist a usual kind of picture' (Goodman, 1968: 33). Through this revisiting and re-experiencing, alternative meanings can be developed, and new understandings can emerge. Arts-based approaches enable a diversity of experience to be shared that can 'disrupt common sense understandings and act as a reminder that there are possibilities for things to be otherwise' (Foster, 2016: 1).

Arts-based research, understood here as socially engaged arts practice (Pool, 2018), can offer an alternative lens through which to consider social cohesion (Facer and Pahl, 2017: 3). Arts-based approaches can offer a more inclusive approach, creating 
space for social cohesion, a space that recognizes that voices may be silenced to account for the differentials in power within the groups with which they work (Norton et al., 2001). When taking a co-produced artistic approach to building social cohesion, it is important to consider power differentials to understand whose voice is heard, whose voice carries power. The power relationships linked to the variety of forms of difference can be uncomfortable to voice (Jones, 2015). Power and inequality are important ethical considerations. The use of art 'does not necessarily mitigate the power relations which can even infiltrate progressive movements' (Foster, 2016: 25). Voice, and the opportunity to share opinion, link to power and inequality within coproduction projects. Yet co-produced arts practices often reveal the interconnections between power and access to resources, and they can offer an opportunity not only to acquire new knowledge but also to re-evaluate the knowledge that they have acquired through more formal research methods. The importance of reflexivity - which this research has sought to engage through reflective semi-structured interviews and through the participatory workshop - is that it can create a space where issues of contested voice, power differentials and artistic identity can be explored.

\section{Reflexivity and co-production: Contested terms}

The collaborative and co-produced artistic approaches to building social cohesion recognize research as co-constituted. In the context of this paper, reflexivity refers to the process of engaging in co-produced reflexive analysis; however, 'its subjective, ambiguous nature is contested' (Finlay, 2002: 531). Reflexivity 'involves reflecting on the way in which research is carried out and understanding how the process of doing research shapes its outcomes' (Hardy et al., 2001: 534; Holland, 1999). In the context of the project, reflexivity was an important means of providing a space where the delicate negotiation between professional and personal identities could be explored. This formed part of recognizing the importance of context as a researcher within the research, of each participant as part of the narrative of interpretation (Angrosino, 2005). For this reason, it was important to make known the multiple roles and membership identities within the collaborative team of community practitioners, artists and academics. During the course of the project, negotiating multiple roles was aided by reflexivity, and a commitment to open and honest dialogue with project participants. Taking this collaborative approach foregrounded issues of power and trust within the wider project that were key to the willing interaction of creativity.

\section{Research methodology}

This paper draws on data and findings from the Taking Yourself Seriously project (described below). The project sought to use artistic approaches as a method of building co-production in three project settings: a school, a community group and a play area. The project began in February 2017 and emerged from a broader Connected Communities Programme that was launched in 2010. The aim of the Connected Communities Programme was to 'fund research projects, partnerships and networks that would create a deeper and richer understanding of "communities" in all their forms and in all the roles they play and have played historically in our lives' (Facer and Enright, 2016: 10). Drawing on this, the Taking Yourself Seriously project aimed to rethink the ways that art is described in community settings, using co-production as a mode of collaborative art. The project aim was framed around artists going into the three community spaces to explore how social cohesion could be re-imagined using arts-based approaches. The project worked with poets, a musician and visual artists 
to explore participants' ability to take themselves and, in so doing, social cohesion, seriously.

The Taking Yourself Seriously project involved artists working with community practitioners in three settings - a school, a community group and an adventure playground - to co-produce art and enact social cohesion. Each setting enacted a variety of artistic approaches to building social cohesion. A partnership was developed with the school, working with Year 8 students. The project developed creative poetry and visual arts workshops to extend and deepen definitions of success. Students were encouraged to create poetry and portraiture that reframed their school and their own experiences as successful, and to reimagine their identity as young people of Rotherham. The community group explored ways in which artistic methodologies supported community-led research, with a focus on the life trajectories of women from Pakistani heritage backgrounds. Poetry and other artistic methodologies were utilized to connect three generations of women's family histories, creating a sense of being between generations. The project used arts-based practice to give deserved recognition to the contribution migrant communities have made to social, cultural and economic life. Collages, artefacts and poetry were points of creativity and reflection for the women, who shared their memories and experiences of Rotherham. The adventure playground community research project explored the idea of social cohesion as created in everyday playtimes. A pirate ship was created as a piece of play equipment, enabling the team to look at ways in which visual modes achieve impact with community groups, and to reflect on how arts methodologies can be used with communities in more effective and ethical ways. This was art as play. The pirate ship was a physical manifestation of building social cohesion, in its offering of a piece of play equipment for young people within a multicultural location.

\section{The artists}

Within this paper, the experiences of five artists within the three project settings are explored. The artists are three poets and two visual artists.

The two visual artists are Zahir Rafiq and Steve Pool. Steve Pool trained in sculpture and now works across multiple visual art forms. He is interested in how art and culture can bring people together and be a part of promoting change. His recent work has explored the idea of an artist's residency as a research method, and the role of creative practice in co-producing knowledge. He works with collaborator Kate Genever within Poly-Technic (poly-technic.co.uk). Their innovative social practice is recognized nationally. Within this project, Steve worked with Pitsmoor Adventure Playground in Sheffield, developing collaborative visual art and play equipment. Zahir Rafiq is an artist from Rotherham, South Yorkshire. He specializes in contemporary Islamic art, where he fuses traditional Islamic motifs with Western artistic styles. With this approach, he sought to express not only a new way of looking at Islamic art, but also his own identity as someone being brought up as a Muslim in Britain. Within this project, Zahir worked in the school, developing self-portraiture with the students as an expression of success.

The three poets are Zanib Rasool, Helen Mort and Andrew Macmillan. Zanib Rasool is a doctoral student at the University of Sheffield and works for Rotherham United Community Sports Trust; her interest is in using creativity and art to engage the voice of young people and other socially excluded groups. Zanib was community researcher on the Imagine project funded by the Economic and Social Research Council (ESRC). She is co-editor of a book published by Policy Press called Re-Imagining 
Contested Communities: Connecting Rotherham through research (2018). She was researcher on Threads of Time, a co-produced participatory arts project funded by the Arts and Humanities Research Council's (AHRC) Connected Communities Festival 2016. Within this project, she has worked in the community setting with three generations of Muslim women, facilitating the development of visual art alongside another artist, and writing poetry with the women on the project. Helen Mort is a poet who has won the Foyle Young Poets Award five times. She has received an Eric Gregory Award from the Society of Authors, and won the Manchester Poetry Prize Young Writer Prize. Helen was also the Derbyshire Poet Laureate for two consecutive years. Her collection, Division Street, won the Fenton Aldeburgh First Collection Prize in 2014. Andrew McMillan is a South Yorkshire-born, Manchester-based poet and academic. His work for the AHRC and in the community is focused on re-centring narratives and destabilizing presumed authorities of certain stories. His own poetry deals with ideas of class, masculinity and physicality. Within this project, Andrew and Helen worked with the school, developing collaborative and individual poetry with the young people.

\section{Co-producing analysis}

\section{Conversations with artists}

The interviews with the artists were semi-structured telephone interviews conducted in autumn 2017, towards the end of the Taking Yourself Seriously project. The interviews offered an opportunity for the artists to reflect on their experiences within the project. A participatory workshop held in winter 2017 sought to discuss and consider the themes that had emerged from the interviews with the artists, and to add the artists' in-depth reflections on these themes. The semi-structured interviews were focused on a short set of five aide-memoire questions that were adapted to suit the interviewees' own understanding and confidence. The defining characteristic of semi-structured interviews is that they have a fluid and flexible structure. They can be differentiated from more formal structured interviews, where the same questions are asked in the same way to all interviewees (Mason, 2010). The five questions considered how the artists felt that they were enacting social cohesion within the project, how co-production had worked within the project, and what might have been done differently. The individual in-depth interviews offered the opportunity to 'delve deeply into social and personal matters' (DiCicco-Bloom and Crabtree, 2006: 315). The semi-structured questions enabled the artists to reflect on the role of co-production within the project, and on what their learning from the project had been in terms of co-producing knowledge and art. Notes were taken during each interview, and a transcript was written up from these notes. This transcript was then emailed to each artist, and they were invited to update the notes to ensure that they accurately reflected their memory of the conversation.

\section{Participatory workshop}

Once some initial themes had been identified from the five semi-structured interviews, a participatory reflection workshop took place. This was aimed at developing coproduced reflections on the research themes and feeding back artistic perspectives on these themes, with a view to developing them or constructing new themes depending on how the session went. This workshop was attended by 12 practitioners from a mixture of artistic, community and academic backgrounds. The role of participatory research in the context of this research paper was to engage the artists to co-produce the research analysis. This workshop shared each of the emergent themes from the 
semi-structured interviews on large A0-sized yellow paper circles. The artists were then asked to respond to the themes using their choice of artistic method. Paints, glue, plasticine and calligraphy pens were supplied, and time was allowed for the artists to respond in their chosen medium. Some artists chose poetry, some paint and others drawing.

\section{Coding and drawing themes}

This paper is a piece of co-produced work, and, as such, the coding of the themes that emerged was a reciprocal process. Themes were discussed and debated during the participatory workshop with the artists, where terms and significant issues for the data analysis were identified through a collective contribution process (Datta et al., 2015). In taking a co-produced approach to analysis, the research has aimed for 'a more critical understanding of the low-lying assumptions, motivations and values that inform research practice' (Tuhiwai Smith, 1999: 1). As a piece of participatory coproduced research, it was important that the research ownership sat with the artistic community - that the artists retained control over the data analysis (Datta et al., 2015) - which reflects this paper's co-produced research methodology. Having considered the artistic and co-produced approaches to research and the research methodology, the paper will now move on to discuss research findings.

\section{Research findings and discussion}

The themes that emerged from the research centred on foregrounding artistic understandings, the value of artistic relationships developing shared understandings, the value of the relationships artists held with communities, the importance of the specificity of artistic knowledge, and the challenges in referencing art as a process over creating an artistic product. The power of the artists within the project is explored throughout the discussion of the findings, exploring artistic control of the project, and how in many cases this was boundaried control. Artistic voice within the project was another theme linked to the development of artistic role. Tensions between community development and artistic perspectives became a further theme, which was linked to how the artists defined roles.

A participatory workshop was held towards the end of the project, in winter 2017. It was attended by the majority of practitioners on the project, the principal investigator, research assistant, artists and community practitioners. The session was framed around the five themes that emerged from the semi-structured interviews. They were written onto five large paper circles and participants were invited to discuss them in groups. This formed part of the group analysis. The participation workshop was an act of co-produced analysis, collaboratively analysing the findings from the semi-structured interviews and drawing additional conclusions from the themes that emerged within the interviews. The workshop reinforced the importance of the agency of each project practitioner (artist, community or academic). The workshop collaborative discussion reinforced the experience of art generating feelings of discomfort, but it was agreed that it was important that practitioners did not feel unsafe. The workshop reinforced the importance of artists working within their community and the value of feeling centred in community, of holding the heart of the community. Power, control and voice were also important; the project did not always get these right, and the reflections at the participatory workshop illustrated this. Power, control and voice are difficult to negotiate within projects, and this is reflected in the research findings of this paper. 


\section{Foregrounding artistic understandings}

Recognizing the complexity of the project, and that the contested nature of the terms 'social cohesion' (Jones, 2015) and 'co-production' entails multiple meanings (Coghlan and Brydon-Miller, 2014), was an area that artists felt could have been developed. Clarifying definitions and understandings of these terms for the artists, recognizing also that artists themselves are not a homogeneous group, was an important reflection from the project. Foregrounding artistic understandings in relation to artistic roles was key to the collaborative foundations of the project. The research found that developing shared understandings of the meaning of terms such as 'social cohesion' and 'co-production' among artists and community members was important. Both terms - 'social cohesion' and 'co-production' - are used with multiple meanings, and they can be interpreted in a variety of ways by artists, community development workers and academics alike. Clarifying understandings enabled the project to refocus power and control away from the academic voices and into the hands of the community artists (Finley, 2008). For one artist, there was a fear that the term 'co-production' could be seen as tokenistic, used for the purposes of obtaining research funding rather than as an egalitarian approach to the research process. This is evidenced by his artistic reflection:

Co-production can be tokenistic and an excuse or a smokescreen or a buzzword. Co-production in the sense of art has its own histories and problems - the single authored work or text is still pretty central to all accepted art production. (Steve Pool, visual artist)

The project found that foregrounding artistic understandings and building a common language would have been helpful from the beginning of the project. Where this did not happen, confusion often emerged, as this artist's reflection illustrates:

Next time, put the artists at the centre of the arts methodologies so that they understand the boundaries and the ethics, so they understand the history, and relationships to process and product; coming in at a later stage means people have different understanding of the project. (Zanib Rasool, poet and community practitioner)

Co-production of the research aims and methods is important to ensure that the framework of the research is co-owned and shaped by the community (Bell and Pahl, 2018). The importance of building shared co-produced understandings is evidenced by the artists' reflections:

I hope that we are using the same definition of social cohesion as the project ... I've not been to the Critical Thinking Group. I might be using the term as a lay person, rather than in the sense that it was intended. (Helen Mort, poet)

Co-production from an artistic perspective can mean different things depending on the art form; for example, if it is a collaborative poem or a shared portrait. Indeed 'unpicking assumptions around collaboration, participation, equality, non-hierarchy and divisions of labour are important' (Bell and Pahl, 2018: 105). In developing new co-produced relationships, especially in the school environment, sharing an understanding of what the term 'co-production' meant was helpful. On reflection, the need to establish this understanding earlier on in the project was a key learning point:

Managing understandings was interesting, what do the school understand by co-production? ... it was nailing down what they [the school] wanted ... 
I don't think anyone actually asked the school that ... What did they think co-production was or could be? (Andrew McMillan, poet)

Agreeing how contested terms are understood among artists and community practitioners was key. Recognizing power differentials, and using the power of institutions such as universities to facilitate benefits for the co-produced project, was seen as a positive for the Taking Yourself Seriously approach to co-production:

Try to get them [the school] to make space for something to happen, we have had to be very pliable and flexible to their needs and just do what we are told to a certain extent, and it's what they needed us to. (Andrew McMillan, poet)

Artistic freedoms were in some settings hampered by process-driven understandings of terms such as 'co-production' and 'social cohesion'. An area for development was how the project has engaged with the artists and how, in the school project in particular, co-production was perceived as having been successful between individual artists and the school, but that between the artists there was further opportunity to co-produce:

There hasn't been so much co-production between arts practitioners. I'm in a different position, I'm from the area, and know the kids and can identify with them. That's the advantage that I've got when I walk in. The other artists were newcomers to the area. We could have done more, and discussed more how we could work together. We should sit down and talk more about how we encourage art work. (Zahir Rafiq, visual artist)

The participatory workshop that co-analysed the interview findings reflected that the capacity of the artists, due to their commitment to help the project and willingness to work flexibly, enabled the project to use artistic approaches to social cohesion. Without this strong goodwill towards the project, and the unwavering commitment of the artists, the project could not have moved forward. Foregrounding the understanding of terms such as 'co-production' and 'social cohesion' early in the project could have ironed out misunderstandings early on, making for a smoother experience for the artists involved in the three projects. Here, clarifying the terms of the research methodology would have been helpful, reflecting how important the research methodology is to the overall research project (Datta et al., 2015). The group that discussed this workshop question shared that the artists they had worked with had not attended the initial two-day workshop at the start of the project. For these artists, working on the project had then been quite hard. One participant made a plasticine flower to illustrate the delicacy of working with the artists. The workshop participants discussed a sense of bewilderment, of unexpected emotions that were brought to the surface by their involvement in the project, and that at times they felt out of their depth. This reflection reveals the fact that taking co-produced approaches to refocusing the power and control with the community (Finley, 2008) is a contested process. It also reflects the complex, layered senses of belonging and identity that emerge from definitions and discussions of social cohesion (Jones, 2015). At one point, one artist withdrew from the project and was brought back into it through extensive mentoring. In terms of artistic control, the artists shared that they had felt challenged by the co-produced process.

Developing shared understandings and recognizing tensions between community development and the artistic contributions were a challenge. Negotiating ideas of social cohesion and community cohesion while trying to be authentic was an important consideration for the artists. The notion of failure was important to all projects; seeing failure through each other's eyes was an important consideration, 
for when writing poetry, it is necessary to fail in order to get better. The notion of the wisdom of the group was an important area for workshop participants here. In the school project, there was a tension between how to use the artists and how they might negotiate their creative activity while recognizing that the school needed the certainty of a lesson plan. There was a tension between what was idealistic and what was practical. The school found it hard to embrace the uncertainty of creativity, seeing the bubbling excitement of students in collaboratively creating poetry as disruptive behaviour. The participants spoke of how the Taking Yourself Seriously project had made them feel uncomfortable; in this sense, the artists had been used within the projects as disrupters.

\section{The value of artistic relationships: Power of the artists; power and trust in communities}

In negotiating shared understandings of key terms and roles within the project, issues of power and trust were fundamental. Who is involved in the research process affects the outcomes of the research (Datta et al., 2015). The artists in the projects were from a variety of backgrounds. Two of the visual artists and one of the poets were from the communities in which their research was based; the other artists were new to the area. This influenced their power within the settings, the levels of trust that they could enact and their approach to their art. The research established that power and trust are key to successful artistic co-production in communities. Communities are multidimensional, and building working relationships between artists and community groups takes time. Recognizing who personally and organizationally holds power within a co-produced project allows for a discussion of how this power is negotiated.

The artists were situated and reflexively engaged with the community spaces in which they were working. The research recognized that the artists in some cases felt vulnerable working in a community development setting, and, likewise, community development workers may have felt unsure of how the artists might work. Clarifying roles and adjusting to the uncertain nature of co-producing artistic roles throughout the project were often uncomfortable for the artists. Some artists felt more power than others in terms of their ability to articulate and define their roles within the project. Here, it is important to reflect that the co-produced aim of refocusing the power and control back into the hands of the community (Finley, 2008) is not without its challenges. The role of art in developing social cohesion is to destabilize and create opportunities for creativity, but this does not necessarily mean that everyone in the project feels equal power. Recognizing these power differentials, and allowing time for creativity to blossom, offered an opportunity for discussion, as Zanib Rasool articulates:

Something that I have learnt about collaborative working is giving the artist time for creative space. There are stages to co-production, but collaboration takes time, and it is important to recognize that artists need time to create. Working in this way gives the artist a lot more freedom and it gives her an opportunity to think through the art and reflect on it. She'd never discussed her art previously and she found the opportunity to talk through her thought process very empowering. (Zanib Rasool, poet and community practitioner)

In allowing time for creative space in co-production, artists' experience of uncertainty can be explored, and vulnerabilities can be shared and discussed. Trust can be built. This trust can then be extended to the artists' relationships with the community. 
Care for those involved in the co-produced research process, artists and participants alike, is important (Bell and Pahl, 2018). This was revealed in the artists' reflections on the importance of developing trusting, safe spaces in which to empower their creativity:

Artists are unique, and you have got to work with them in a tentative way; some artists also lack confidence and if there's too many people around them, they can't focus. Knowing the artist has been really important to the co-productive processes, because the working relationship was already established. (Zanib Rasool, poet and community practitioner)

Supportive facilitation by key members of the project team, who not only were experienced in co-production but also had established working relationships with the artists, was important to the success of the project. As the project developed, it became clear that managing the collaborative space was a positive way to support and facilitate co-production, especially when working with artists for whom it was a new way of working:

There is a need to develop more collaborative space and then leave the artist to work within their creative space. [l have] taken on the role of co-production manager - recognizing the various stages of the creative process and managing that with the artist. Creating space and time is one of the key areas that are essential to co-production. (Zanib Rasool, poet and community practitioner)

This development of creative space where artistic understandings of social cohesion and co-production were foregrounded, allowing for artistic freedom, was key to the project's arts-based approach to building social cohesion. Working with artists who had existing strong bonds of trust within communities added extra depth to the work. These artists knew their local area, and being local residents added an accountability to the process of building social cohesion. Trust was a key element to the facilitation of effective co-produced relationships. Co-production on the project worked best when the project worked within long-term established relationships, where trust already existed. This trust enabled open conversation and supportive listening, and it created a safe space within the project within which the artists felt that they were valued and that their artistic reflections were welcomed. The artist's insider roles (Corbin Dwyer and Buckle, 2009), when foregrounded, were points where trust developed.

The multiple roles of the artists within the project were discussed within the participatory co-produced analysis workshop. The importance of communication was reiterated, with communication discussed as taking place at a range of levels. The participants created multiple plasticine spheres to represent the multiple heads and roles the artist has within the community. With the insider and outsider identities (Corbin Dwyer and Buckle, 2009) taken on by the artists working in their own communities, they mixed their personal and professional roles through the choice to work within their own neighbourhoods. This involved managing personal opinions and professional beliefs. In this sense, the importance of holding the trust of the local community, and living and working within their own community, can speak to an integrity as an artist, but it also required an awareness and negotiation of local politics. In being of the community, there was an authentic voice from the artist for the community, which contributed to the success of the project. An artist can be deeply professional and passionate about their endeavours, but if they have not got the ear of the community, the community will see through them. The adventure playground artistic practice was very inclusive, building a 
cardboard model with the children and young people. The additional advantage was the extra funding that working with the artists enabled the adventure playground to access. Here, the artists reflected that their capacity for becoming at once an insider and outsider (ibid.) to the project allowed them to embody multiple roles that reflected the complexity of the co-produced artistic approaches to building social cohesion.

\section{Creating collaborative spaces: 'Doing art your own way'}

Using specific artistic methodologies, such as poetry and portraiture, to ask questions and to explore social cohesion offered an opportunity to develop safe spaces. These specific artistic methodologies allowed artists to offer an alternative way of thinking about social cohesion. Recognizing that the artistic methodologies have complex histories (Pool, 2018), these specific approaches developed culturally shaped artistic approaches, creating a safe form of reflection about the area in which each project was based. For example, poetry in the school context built a common purpose with the young people, as this artist reflects:

The poetry workshop space was a safe space to begin to get on with a common purpose. Through that temporary entry into the space they [the young people in the school project] begin to see each other as having similarities that they can use to build on. (Andrew McMillan, poet)

Building positive working relationships in order to enact this safe space was important to co-production in the project. Some relationships were already established and long term, such as the women's community project. Other projects were new relationships, such as the school. In all cases, co-production involved the development of listening relationships. For one artist, working specifically in the community in which he lived reflected a personal ethical movement in his artistic journey:

After so many projects that I felt compromised in, I needed to find a place where I could work that wasn't so personally ethically challenged. For me ... building play equipment for kids to play on in my own community, a community that sits on a history of violence both here and in people's origins, is at a straightforward level useful ... Trying to be embedded somewhere, and choosing not to make the distinction between art and community in that sense. (Steve Pool, visual artist)

Taking a co-produced approach and fashioning the projects around the artistic process, rather than around social cohesion, meant that social cohesion emerged organically as a theme through the projects, valuing non-academic voices (Facer and Pahl, 2017), as seen in this reflection:

It wasn't me as a brown artist talking about my ethnicity, but about me being there as an artist. Not to impose social cohesion on people, but social cohesion was a side effect of my work. (Zahir Rafiq, visual artist)

The specificity of the art forms linked artefacts to poetry to develop safe spaces where conversations could move towards building a narrative of social cohesion. Using artefacts to discuss memory and to reminisce offered an alternative means of reflection for the women's group. It also offered a means to facilitate conversation and to draw memories from everyday objects:

It made me rethink the art around me; art in woven beds and art in pottery.

What things and objects mean and are bits of memories from previous 
generations. We are creating a visual narrative of these women's lives, using art as a tool to do that. (Zanib Rasool, poet and community practitioner)

Through the use of artistic methods, social cohesion was organic. The use of artistic methods allowed an alternative perspective on the world (Foster, 2016), opening up conversations:

In the creation of a temporary space, the meta-role of the project has allowed the school to see enacted social cohesion within the classroom/ writing group ... A safe space is created away from individual identities. It is the creation of a safe space to temporarily decide to unite along the same project. (Andrew McMillan, poet)

Artistic approaches, and the specificity of the art used, such as poetry, opened up informal spaces of inclusion where social cohesion began to be enacted. The research found that the culturally shaped power of the specific art forms allowed social cohesion to emerge organically through the co-produced process of creating art. However, here a tension emerged. Was social cohesion created in the process of creating the art?

The power difference within the project was discussed often at the writing retreat at the end of the projects, and the workshop participants referenced this. The workshop participants felt that it was important to recognize what everyone brought to the room. A big part of the project had been co-production; however, this was not the case in the adventure playground. The adventure playground was about the input of an idea that the artist felt would fire and stimulate the children's imagination. It was the act of stimulating their imagination, and what they would do next, that was the collaborative venture. The adventure playground project used the pirate ship as a utopian idea (Pool, 2018). For the artistic work at the adventure playground, the art had been an act of labour; the co-production had been in enabling the play to happen, and in facilitating the childhood imaginative play. The creation of the pirate ship, not as a work of art but as a space for creative play, opened up the experience of art to be perhaps a piece of collaborative theatre, which holds notions of identity, beauty, feeling and poetry as visual art (Pool, 2018). Other forms of artistic expression may not hold those in the same way.

\section{A process or a product? Artistic roles}

The project questioned the role of art in co-production. As the project was completed, a further discussion emerged: artists, academics and community practitioners began to ask, what does art do? The project recognized the history of socially engaged art (Pool, 2018) in choosing to work in a co-produced way and engage the project team. The artists, academics and community practitioners had a variety of artistic backgrounds: some were familiar with the history of art, others less so. A tension emerged between art as a process and the community desire for a physical product as an act of reciprocity. Choosing to use art as a framework for social cohesion means valuing and holding the art at the centre of the project. As the project continued, it became clear that working with the artists offered a way of seeing what might not always be visible (Goodman, 1968). The research reflected upon how artistic methods help us to see things in slow motion. During the project work, sometimes the variety of voices - from academic to community development worker to artist - could favour those who were more able to articulate their views rather than working to value, listen and collaborate to focus on the art. This is discussed by Foster (2016), who reflects that the use of art does not always equalize power relations. However, by focusing on the art, the cohesion can 
emerge organically from the artistic method, which is what is so valuable about using artistic methodologies for social cohesion:

The social cohesion just happened, it wasn't the main factor. It just happened ... The main factor was talking about my art. Social cohesion developed from the art. It was the very first time for me, to feel as an artist, to go into school and just talk about my art ... Because social cohesion wasn't imposed. I just started with my identity as an artist; my daughter advised me to just be myself, to just teach what I know. (Zahir Rafiq, visual artist)

Here, tensions emerged about whether it was the process of creating and the use of artistic techniques that resulted in the co-produced building of social cohesion, or whether in fact it was as an act of reciprocity, as a thank you for the time and effort shared by those who participated in the project. Indeed, as discussed earlier, power relationships are linked to a variety of forms of difference, and they can be hard to voice (Jones, 2015). For some of the artists interviewed, it was important to create a product. In the case of the adventure playground, a product - the pirate ship - was created as part of the artistic process. In the case of the other projects, there was discussion of missed opportunities to value the work we completed, for example, the creation of a book of poems or a photographic record of completed activities.

The reality of working on a community project, and recognizing the complexity of the issues that the community are working through, was an important power consideration for the workshop participants. Some artists were based locally; others were new to the area. Balancing the intersectionality of power relationships was a challenge at times for the artists. This balancing was discussed in terms of balancing the notion of artists being used instrumentally and artists as co-producers of knowledge. It was felt by workshop participants that these roles had fluctuated within the project. There were several artists involved in the project, and different artists felt different levels of power at different times. Here it is important to recognize that the unequal distribution of power within co-produced work can exist despite the best intentions of project participants (Foster, 2016). Refocusing the power and control back in the hands of the community (Finley, 2008) is not without its challenges. Workshop participants shared that they would have liked to feel that they had the power within the project to commit to an artistic product as part of the process, for example, a booklet of poetry as a thank you to participants for their commitment to the project. As part of the participatory workshop, the group considering artistic power within the project created a booklet of Post-it notes that illustrated the layered intersectionality of co-production within the projects. They shared that power as a concept within the projects felt very complex and not easy to express within the experience of the project.

Key themes that have emerged from the research centre on foregrounding artistic understandings and relationships, valuing artistic expertise, and the tension between a socially engaged artistic process and community desire for an artistic product. The importance of recognizing the power of artists, and understanding the intersectionality of the power inequalities within co-produced relationships, was identified. Artistic control and the boundaries of artistic power was another theme that emerged from the research; these were reflected in tensions between the approaches and experiences of community development workers and artistic contributions. The importance of facilitating artistic voice within the project and allowing an opportunity for artistic voice were further themes. To summarize, co-producing artistic approaches to social cohesion is a complex, multilayered and sometimes fragile process, but 
recognizing, discussing and sharing understandings of the role of power and voice within the co-produced project enable effective team communication.

\section{Conclusion}

This paper has considered arts methodologies as an approach to building social cohesion. Using arts methodologies as an approach to building social cohesion is to ask questions and create connections from alternative angles; it is a process of listening to a community. Foregrounding artistic methodologies on a social cohesion project has developed consideration of the power that artists hold within a project (Foster, 2016; Facer and Pahl, 2017). The artistic control of a project can often be boundaried control. This paper has identified the tensions in the working approaches between community development workers and artistic contributions. Defining roles as an artist and establishing a strong artistic voice within a project were important themes that emerged from both the semi-structured interviews and the participatory reflection workshop. Negotiating the artists' roles as insiders and outsiders (Corbin Dwyer and Buckle, 2009) to the project added a further layer of complexity. There were tensions between the artists' wish for artistic freedom and for freedom of expression, and the reality that boundaries existed within each of the three projects.

Key themes identified in this paper centre on the importance of recognizing the power of artists and understanding the intersectionality of the power inequalities within co-produced relationships. These themes are framed around four linked learning points. First, the importance of foregrounding artistic understandings early in the coproduced artistic project. Second, the value of artistic relationships with the community and the knowledge that they bring. Third, valuing specific artistic practices and the power and voice attached to perceptions of varying art forms. Finally, the debate over whether the approach should create an artistic product or if taking artistic approaches as a process is actually where the value lies. The contested nature of artistic control, and the boundaries of artistic power, emerged from the research; this was reflected in tensions between the approaches and experiences of community development workers and artistic contributions. Co-production is not equal, and power inequalities exist within artistic methodologies as well as within wider society. The importance of facilitating artistic voice within the project, and of allowing an opportunity for artistic voice, emerged throughout discussions with the five artists.

This paper seeks to highlight and discuss these themes, and to offer an honest consideration of the value and challenges of using artistic methodologies for social cohesion. The paper discusses this approach from the perspectives of the five artists involved in the project. The key learning from this research is that it is important to engage artists in co-produced research from the beginning, to recognize the variations of power held in a project and to take steps to empower artistic voice. Power and truth are multidimensional concepts, and when using artistic approaches, knowing whose knowledge counts and where understandings are located are key to artistic work within communities (Campbell et al., 2018). Valuing the artists is central; artists can offer an alternative perspective on community relationships and social cohesion (Pool, 2018). The arts offer the power of the imagination, the creative freedom to see beyond a current reality, in order to build a vision of social cohesion (Foster, 2016). To conclude, co-producing artistic approaches to social cohesion is a complex, multilayered and sometimes fragile process, but recognizing, discussing and sharing understandings of role, power and voice within the co-produced voice enables effective team communication. 


\section{Acknowledgements}

This work was funded by the Arts and Humanities Research Council (AHRC) number: AH/P009573/1. The principal investigator was Kate Pahl, with Zanib Rasool and Andrew McMillan as co-investigators and Steve Pool, Zahir Rafiq, Nazia Latif, Helen Mort and John Ball as artists. A critical thinking group chaired by Mike Fitter supported the work, and John Diamond was the mentor on the project. It was conducted in collaboration with the Association for Research in the Voluntary and Community Sector (ARVAC), and Pitsmoor Adventure Playground and Clifton Secondary School in Rotherham. Katy Goldstraw was the research associate on the project. This article is developed from a literature review that previously appeared on the ARVAC website and summarized the desk-based learning from the project.

\section{Notes on the contributors}

Katy Goldstraw is a senior lecturer in health and social care at Staffordshire University and also works independently as a participatory anti-poverty specialist. She has worked in higher education and the voluntary sector throughout her career, writing on voluntary and community sector assets, citizens' voice and participatory research. She has a particular research interest in using participatory arts-based research methods to include and empower the voices of previously unheard communities.

Andrew McMillan is a Manchester-based poet and academic. He is a senior lecturer at the Manchester Writing School at Manchester Metropolitan University. His work for the AHRC and in the community is focused on re-centring narratives and destabilizing presumed authorities of certain stories. His own poetry deals with ideas of class, masculinity and physicality. Within this project, Andrew and Helen Mort worked with the school, developing collaborative and individual poetry with the young people.

Helen Mort is a lecturer in creative writing in the Department of English and Manchester Writing School at Manchester Metropolitan University. Her poetry collection Division Street (Chatto and Windus, 2013) won the Fenton Aldeburgh Prize and was shortlisted for the Costa Prize and T.S. Eliot Prize. She has also published a novel, Black Car Burning (Vintage, 2019), and a short story collection, Exire (Wrecking Ball, 2018). Her play, Medusa, toured with Proper Job Theatre Company in autumn 2017.

Professor Kate Pahl is Faculty Head of Research and Knowledge Exchange and Head of the Education and Social Research Institute at Manchester Metropolitan University. She was employed by the Council for Racial Equality in London for many years as an outreach worker in adult literacy. Her research is concerned with literacy practices in communities, drawing on arts and humanities methodologies. She has been involved with many projects funded through the AHRC Connected Communities Programme, all co-produced with community partners and drawing on the knowledge within communities to work together to produce living knowledge.

Steve Pool trained in sculpture and now works across multiple visual art forms. $\mathrm{He}$ is interested in how art and culture can bring people together and be a part of promoting change. His recent work has explored the idea of an artist's residency as a research method, and the role of creative practice in co-producing knowledge. He works with collaborator Kate Genever within Poly-Technic (poly-technic.co.uk). Their innovative social practice is recognized nationally. Within this project, Steve worked 
with Pitsmoor Adventure Playground in Sheffield, developing collaborative visual art and play equipment.

Zahir Rafiq is an artist from Rotherham, South Yorkshire. He specializes in contemporary Islamic art, where he fuses traditional Islamic motifs with Western artistic styles. With this approach, he seeks to express not only a new way of looking at Islamic art, but also his own identity as someone brought up as a Muslim in Britain. Within this project, Zahir worked in the school, developing self-portraiture with the students as an expression of success.

Zanib Rasool is a doctoral student on the EdD programme at the University of Sheffield and is the Partnership and Development Manager for the charity Rotherham United Community Sports Trust. Zanib was community researcher on the Imagine project funded by the ESRC. She is co-editor of Re-Imagining Contested Communities: Connecting Rotherham through research (Policy Press, 2018). She was researcher on Threads of Time, a co-produced participatory arts project funded by the AHRC Connected Communities Festival 2016. Within this project, she facilitated the development of visual art and poetry with three generations of Muslim women.

\section{References}

Angrosino, M.V. (2005) 'Recontextualizing observation: Ethnography, pedagogy, and the prospects for a progressive political agenda'. In Denzin, N.K. and Lincoln, Y.S. (eds) The SAGE Handbook of Qualitative Research. 3rd ed. Thousand Oaks, CA: SAGE Publications, 729-46.

Bell, D.M. and Pahl, K. (2018) 'Co-production: Towards a utopian approach'. International Journal of Social Research Methodology, 21 (1), 105-17. Online. https://doi.org/10.1080/13645579.2017.1348581

Bishop, C. (2004) 'Antagonism and relational aesthetics'. October, 110, 51-79.

Campbell, E., Pahl, K., Pente, E. and Rasool, Z. (eds) (2018) Re-Imagining Contested Communities: Connecting Rotherham through research. Bristol: Policy Press.

Chan, J., To, H.-P. and Chan, E. (2006) 'Reconsidering social cohesion: Developing a definition and analytical framework for empirical research'. Social Indicators Research, 75, 273-302. Online. https://doi.org/10.1007/s11205-005-2118-1

Coghlan, D. and Brydon-Miller, M. (eds) (2014) The SAGE Encyclopedia of Action Research. London: SAGE Publications.

Corbin Dwyer, S. and Buckle, J.L. (2009) 'The space between: On being an insider-outsider in qualitative research'. Journal of Qualitative Methods, 8 (1), 54-63. Online. https://doi.org/10.1177/160940690900800105

Crenshaw, K. (1991) 'Mapping the margins: Intersectionality, identity politics, and violence against women of color'. Stanford Law Review, 43 (6), 1241-99. Online. https://doi.org/10.2307/ 1229039

Datta, R., Khyang, N.U., Khyang, H.K.P., Kheyang, H.A.P., Khyang, M.C. and Chapola, J. (2015) 'Participatory action research and researcher's responsibilities: An experience with an indigenous community'. International Journal of Social Research Methodology, 18 (6), 581-99. Online. https://doi.org/10.1080/13645579.2014.927492

Delhey, J. (2007) 'Do enlargements make the European Union less cohesive? An analysis of trust between EU nationalities'. Journal of Common Market Studies, 45 (2), 253-79. Online. https://doi.org/10.1111/j.1468-5965.2007.00711.x

DiCicco-Bloom, B. and Crabtree, B.F. (2006) 'The qualitative research interview'. Medical Education, 40 (4), 314-21. Online. https://doi.org/10.1111/j.1365-2929.2006.02418.x

Etzioni, A. (1993) The Spirit of Community: Rights, responsibilities, and the communitarian agenda. London: Fontana Press.

Facer, K. and Enright, B. (2016) Creating Living Knowledge: The Connected Communities Programme, community-university relationships and the participatory turn in the production of knowledge. Bristol: University of Bristol and AHRC Connected Communities Programme.

Facer, K. and Pahl, K. (eds) (2017) Valuing Interdisciplinary Collaborative Research: Beyond impact. Bristol: Policy Press. 
Finlay, L. (2002) '“Outing" the researcher: The provenance, process, and practice of reflexivity'. Qualitative Health Research, 12 (4), 531-45. Online. https://doi.org/10.1177/104973202129120052

Finley, S. (2008) 'Arts-based research'. In Knowles, J.G. and Cole, A.L. (eds) Handbook of the Arts in Qualitative Research: Perspectives, methodologies, examples, and issues. Thousand Oaks, CA: SAGE Publications, 71-81.

Foster, V. (2012) 'The pleasure principle: Employing arts-based methods in social work research'. European Journal of Social Work, 15 (4), 532-45. Online. https://doi.org/10.1080/13691457.2012. 702311

Foster, V. (2016) Collaborative Arts-Based Research for Social Justice. London: Routledge.

Goodman, N. (1968) Languages of Art: An approach to a theory of symbols. Indianapolis: Bobbs-Merrill.

Hancock, L., Mooney, G. and Neal, S. (2012) 'Crisis social policy and the resilience of the concept of community'. Critical Social Policy, 32 (3), 343-64. Online. https://doi.org/10.1177/0261018312444410

Hardy, C., Phillips, N. and Clegg, S. (2001) 'Reflexivity in organization and management theory: A study of the production of the research "subject"'. Human Relations, 54 (5), 531-60. Online. https://doi.org/10.1177/0018726701545001

Hirsch, N. and Miessen, M. (eds) (2012) The Space of Agonism: Markus Miessen in conversation with Chantal Mouffe. Berlin: Sternberg Press.

Holland, R. (1999) 'Reflexivity'. Human Relations, 52 (4), 463-84. Online. https://doi.org/10.1177/ 001872679905200403

Jones, H. (2015) Negotiating Cohesion, Inequality and Change: Uncomfortable positions in local government. Bristol: Policy Press.

Kester, G.H. (2004) Conversation Pieces: Community and communication in modern art. Berkeley: University of California Press.

Kocur, Z. and Leung, S. (eds) (2005) Theory in Contemporary Art since 1985. Oxford: Blackwell.

Kumasi, K.D. (2011) 'Critical race theory and education: Mapping a legacy of activism and scholarship'. In Levinson, B.A.U., Gross, J.P.K., Hanks, C., Heimer Dadds, J., Kumasi, K.D., Link, J. and Metro-Roland, D. Beyond Critique: Exploring critical social theories and education. Boulder, CO: Paradigm Publishers, 196-219.

Kwon, M. (2002) One Place after Another: Site-specific art and locational identity. Cambridge, MA: MIT Press.

Mason, M. (2010) 'Sample size and saturation in PhD studies using qualitative interviews'. Forum: Qualitative Social Research, 11 (3), Article 8, 1-19. Online. https://doi.org/10.17169/fqs11.3.1428

Norton, A., Bird, B., Brock, K., Kakande, M. and Turk, C. (2001) A Rough Guide to PPAs: Participatory poverty assessment: An introduction to theory and practice. London: Overseas Development Institute.

Pahl, K. and Goldstraw, K. (2018) Taking Yourself Seriously: Arts methodologies for social cohesion. London: Association for Research in the Voluntary and Community Sector. Online. http://arvac. org.uk/wp-content/uploads/2018/01/ARVAC-key-findings-1.pdf (accessed 7 October 2019).

Pool, S. (2018) Everything and Nothing is Up for Grabs: Using artistic methods within participatory research (Connected Communities Foundation Series). Bristol: University of Bristol and AHRC Connected Communities Programme.

Putnam, R.D. (2000) Bowling Alone: The collapse and revival of American community. New York: Simon and Schuster.

Reason, P. (1998) 'Three approaches to participative inquiry'. In Denzin, N.K. and Lincoln, Y.S. (eds) Strategies of Qualitative Inquiry. Thousand Oaks, CA: SAGE Publications, 261-91.

Sage, D. (2012) 'A challenge to liberalism? The communitarianism of the Big Society and Blue Labour'. Critical Social Policy, 32 (3), 365-82. Online. https://doi.org/10.1177/0261018312444411

Schiefer, D. and Van der Noll, J. (2017) 'The essentials of social cohesion: A literature review'. Social Indicators Research, 132, 579-603. Online. https://doi.org/10.1007/s11205-016-1314-5

Sparke, M. (2008) 'Political geography - political geographies of globalization III: Resistance'. Progress in Human Geography, 32 (3), 423-40. Online. https://doi.org/10.1177/0309132507086878

Tuhiwai Smith, L. (1999) Decolonizing Methodologies: Research and indigenous peoples. London: Zed Books.

Vasudevan, L. (2011) 'An invitation to unknowing'. Teachers College Record, 113 (6), 1154-74.

Walby, S. (1990) Theorizing Patriarchy. Oxford: Blackwell. 